\title{
BASES DA ATUAL AUSÊNCIA DE SENTIDO ÉTICO NA CIÊNCIA
}

\author{
Angélica Lyra de Araújo \\ Aluna do Curso de Especialização em \\ Comunicação Popular e Comunitária na UEL \\ E-mail: lyradearaujo@yahoo.com
}

\section{Resumo}

Esta comunicação de pesquisa apresenta uma discussão sobre como e por que a ciência e a ética encontram-se separadas atualmente. Trataremos acerca da formação de uma racionalidade científica que se pretendeu neutra eticamente, e conseqüências socioculturais dessa postura das ciências modernas. Nosso estudo pauta-se nas análises desenvolvidas pela Teoria Crítica sobre razão e modernidade, principalmente no conceito de instrumentalização. Nesta mesma perspectiva, faremos também algumas considerações sobre a questão da ideologia presente nas ciências, isto é, sobre a manipulação das ciências em defesa de interesses econômico-políticos da classe hegemônica. Instrumentalização e uso ideológico serão evidenciados como processos que geraram a ausência de sentido ético nas ciências, tornando-as uma ameaça a todos os seres vivos do planeta, fenômeno que indica a necessidade premente da reflexão ética sobre os poderes e limites das ciências.

Palavras-chave: ciência; razão moderna; instrumentalização; ideologia;Ética.

ara compreendermos o sentido da ciência, devemos primeiramente analisar a idéia de razão. A ciência e a racionalidade moderna estão uma para a outra, assim como a sociedade está para o indivíduo e vice-versa. Nesta análise, usaremos alguns estudos que apontaram elementos das implicações da ciência no pensamento e nas atitudes dos seres humanos que se encontram mergulhados num contexto da razão. 
A grande dúvida, no entanto, é saber qual o conceito de razão que o indivíduo vivencia no seu meio, levando em consideração os seus interesses particulares ou do grupo que representa. E isto é importante, segundo Horkheimer (1977, p.119), já que "todo ser humano entra em contato com este aspecto tirânico da civilização a partir do seu nascimento". Sabemos, portanto, que este aspecto da civilização detentora de uma razão instrumental, em cuja configuração está a busca da certeza científica, tem incomodado socioculturalmente a humanidade.

Desta forma, Horkheimer busca em sua análise demonstrar quanto o mundo moderno vive desencantado de sua aparência e totalmente dependente de uma racionalidade vista como a "maldição da coisificação demoníaca e do isolamento mortal". (HABERMAS, 1989, p.139). Poderíamos dizer, que esta maldição acaba, por sua vez, expulsando a moral e o direito da sua esfera, possuindo então o domínio do poder em sua essência.

\section{Instrumentalidade Racional Científica}

Horkheimer (1977, p.15) na sua obra Para a Critica da Razão Instrumental demonstra que o ser humano ao ser questionado sobre o significado da razão, se vê em uma situação confusa; para ele o próprio conceito se explica por si mesmo e age naturalmente, já que "as coisas racionais são as coisas úteis e que todo homem racional deve estar em condições de discernir o que é mais útil".. Isto, na maioria das vezes, revela que o indivíduo define suas atitudes de acordo com o seu meio e a sua capacidade de entender o que é mais útil não se preocupando que possa existir algo ideologicamente impregnado em suas atitudes.

Sobre isso, Habermas (1989, p.149), diz que com o conceito de razão instrumental Horkheimer e Adorno pretendem mostrar o tanto que o pensamento racional usurpou o lugar da razão. Para estes autores, "a razão enquanto instrumental assimilou ao poder, renunciado a sua força crítica - este é o último desmascaramento de uma critica ideológica aplicada a si mesma”.

Ainda para Horkheimer (1977), a formação da razão conduz a um paradoxo. $\mathrm{O}$ antagonismo destruidor entre o indivíduo e a natureza é o 
ponto marcante que traduz a história da civilização burguesa sintetizado, assim como um mero instrumento de dominação.

Neste caso, podemos perceber, juntamente com Ianni (1989), que a burguesia parece ter sido a grande cultivadora da razão instrumental, porque esta abria o espaço para o estabelecimento da ideologia dos interesses burgueses.

Portanto, instrumentalizar a razão foi o meio encontrado pela burguesia para transformar a revolução burguesa e se impor como classe legítima. Os esforços da humanidade em dominar a natureza refletem também na história de dominação do indivíduo pelo próprio indivíduo, e em nenhum momento o indivíduo se vê livre do domínio social.

Embora a razão conceitual seja um conceito, uma idéia invisível, ela se torna palpável nas atitudes do indivíduo, influenciando as decisões e o comportamento humano. Em outras palavras, poderíamos dizer que "razão deve regular nossas decisões e nossas relações com os outros homens e com a natureza" (HORKHEIMER, 1977, p.21). Além disso, a razão é mais do que um elo de equilíbrio entre meios e fins. Trata-se de um instrumento capaz de entender os fins e até mesmo determiná-los, conduzindo, por exemplo, reflexões acerca das relações sociais e culturais, como também sobre a própria reprodução da razão dentro das estruturas básicas das sociedades.

É ainda pertinente dizermos que a razão, enquanto instrumental de ação política e econômica, "[...] serve a qualquer desejo particular, seja ela boa ou má. É um instrumento para todas as esferas da sociedade [...]. A razão jamais se dirigiu verdadeiramente a realidade social [...] Tem, portanto, renunciado a sua tarefa de julgar os atos humanos e o modo de viver do homem" (HORKHEIMER, 1977, p.21).

A instrumentalização para Horkheimer se dá quando a razão deixa de lado a sua autonomia e, sobretudo, o seu potencial crítico, ressurgindo, então, como dependente do processo social. Desde que a razão passou a ser um meio de dominação da natureza humana e extrahumana, foram em vão todas as tentativas de descobrir a verdade e até mesmo aquelas de construção de uma razão crítica emancipatória. $\mathrm{O}$ que vemos é que "[...] a natureza é concebida hoje mais do que nunca como uma mera ferramenta do homem. A natureza é um objeto de uma exploração total, que não conhece nenhum parâmetro instituído por 
uma razão" (HORKHEIMER, 1977, p.118). Assim, a história da civilização nasce de um ato de violência e de opressão, no qual padece tanto a natureza quanto o indivíduo inserido na sociedade.

Adorno enriquece ainda mais essa análise ao dizer que na relação entre natureza e indivíduo tem-se algo dialético, porque ambas são idênticas e padecem da mesma opressão. Isto é, "o domínio sobre a natureza esta ligado a uma dominação introjetada do homem sobre o homem que exerce o sujeito na sua própria natureza" (ADORNO, 1971, p.152).

Dessa forma, a crise pela qual passa a razão consiste na maneira como o pensamento deixou de conceber uma objetividade, naturalizando todo conflito de interesse e toda estrutura de sociedade moderna. É evidente que esta crise também afeta a racionalidade do indivíduo, já que ele é um produto do pensamento da razão instrumental.

Dentro deste contexto, Horkheimer também inclui em sua análise a idéia de razão objetiva e subjetiva. Ambas têm existido desde o princípio e aos poucos foram-se alterando ao longo do processo histórico. Elas têm contribuído para aquilo por que tanto o ser humano anseia: dominar a natureza e o outro. Mais uma vez a razão se destaca. Ela se torna contrária à vida e reacionária à modernidade, provocando o caos na natureza e nas relações humanas. Horkheimer (1977, p.16) argumenta:

A razão objetiva aspira-se a desenvolver em um sistema vasto de uma hierarquia de um todo, incluindo o homem e seus fins. $\mathrm{O}$ grau de racionalidade da vida do homem poderia determinar-se conforme a sua harmonia com esta totalidade. A estrutura objetiva desta é não só o homem e seus fins - deveria servir de pauta para os pensamentos e ações individuais.

A razão subjetiva se preocupa somente com os meios e fins, com a adequação de modos de procedimento [...] Pouca importância tem para ela a questão dos objetivos como tais se são racionais ou não [...]. Em última instância a rażão subjetiva resulta ser a capacidade de calcular probabilidades e de adequar assim os meios corretos a um fim já dado (p.15-17).

Ela, portanto não leva em consideração a questão ética no alcance dos objetivos. De modo geral, Horkheimer (1977, p.129) nos 
permite compreender que as repressões dos desejos individuais na sociedade são caracterizadas por uma irracionalidade que induz o ser a desejar o poder sobre as coisas. Ele inicia a busca frenética pela dominação, por ser "o poder é o único que realmente o respeitam e que tratam o de imitar". Isto causa conseqüentemente uma perpetuação da razão instrumentalizada, pois o indivíduo, ao buscar o domínio das coisas, compartilha do espírito de uma razão já formalizada e opressora por excelência.

Barcellona (1995, p.121) esclarece perfeitamente esta situação quando afirma:

O desejo torna-se anônimo e repetitivo, como a reprodução de uma obra de arte [...]. A razão formal, instrumental e calculista nos deu homogeneidade à reprodução sistêmica como fim em si mesma e escavou um abismo entre o sistema e a vida, entre o sistema e o sentido. O homo faber, na sua extrema vontade de controle da natureza e da corporização vivente, produziu apenas a imensa positivização do sistema e da técnica.

Com efeito, o sujeito torna-se um prisioneiro deste pensamento racionalmente escravizante. Ele não consegue mais fazer uso de suas habilidades intelectuais críticas, sendo induzido a desejar cada vez mais o poder, em todos os sentidos da palavra. O indivíduo acaba irracional ou até racionalmente cedendo à razão instrumental, já que ele se esforça para avançar, mas não chega a lugar algum. É por isso que Habermas (1998, p.180), acrescenta que a "razão instrumental que permeia toda a sociedade não pode ser superada dentro da esfera da mesma sociedade". Conseqüentemente, acaba ocorrendo uma mutilação dos valores e da vida de modo geral, terminando como sempre vítima da própria razão, cuja existência se deu como expressão de sua criação.

Diante dessa breve exposição, podemos perceber que a razão, na nossa civilização, é caracterizada como uma racionalidade perversa e dominadora. Ao invés da razão ser vista como no Iluminismo - instrumento emancipatório - ela é desmascarada como a desrazão e revelada como uma vontade de dominação. É por isso, que Oliveira afirma que "o avanço do processo de racionalização significa, modernamente, o avanço da perda de sentido e da liberdade na vida humana, portanto o avanço 
do absurdo" (p.21). E quanto mais o sujeito caminha em busca da ciência moderna, mais ele se despoja de sentido. Essa marca de experiência de perda de sentido da vida, ameaça não somente a natureza e a humanidade, mas, sobretudo, a própria vida humana em sua sobrevivência.

Temos agora, uma grande dúvida: será que caminhamos para a nossa própria destruição? Ou, é possível viver sem a influência da razão instrumental?

Retornemos a Horkheimer. Ele nos fala do processo da emancipação do homem como um destino do mundo que o circunda, dependendo de pessoas esclarecidas e dispostas a lutar contra este enraizado sistema racional. De certo modo, a emancipação crítica é o mesmo que a conscientização e o direcionamento que queremos dar à humanidade. Convém dizermos ainda, que a práxis racional da pessoa humana precisa ser recuperada na integridade de seus momentos, sendo possível somente com a transformação do pensamento racional. Do ponto de vista de Freud (1948, p.1299), "o homem não pode permanecer eternamente menino, tem que sair algum dia para a vida, a dura 'vida inimiga'. Esta seria a "educação para a realidade""

E, para melhor esclarecermos esta problemática, faremos a seguir uma reflexão da ciência na modernidade. Sobre isso Adorno (1999, p.43) comenta que "não há ser no mundo em que a ciência não possa penetrar, mas aquilo em que a ciência pode penetrar não é o ser".

\section{Ideologia ${ }^{1}$ na Ciência Moderna}

Iniciemos a seguinte reflexão sobre ciência e ideologia na modernidade com base na leitura da obra os Fundamentos da Bioética, de Engelhardt (1998). Segundo este autor, a modernidade é uma palavra

' A palavra ideologia neste texto possui conotações marxianas. Engelhardt (1998, p.22) diz que a ideologia no sentido marxiano é "uma falsa consciência, que é falsa ao canonizar um conjunto de arranjos políticos, sociais e econômicos condicionados de uma maneira histórica particular... A partir dessa perspectiva, compreendemos que "todas as ideologias nascem de uma única raiz, ou seja, a psicologia de determinada época, característica dessa época em particular, a totalidade de seus modos, costumes, morais, sentimentos, pontos de vista, aspirações e ideais" (BOGUSLAVSKY apud. ENGELHARDT, 1998, p.23). 
ambígua. Ela ideologicamente identifica um primeiro período histórico, chamado Idade Média, mais explicitamente depois do Renascimento e da Reforma. Este período caracteriza o início da Idade Moderna, cuja ação se volta para a cultura européia ocidental confirmando os seus poderes sobre o mundo primitivo. A modernidade possui extrema confiança nas ciências exatas, biológicas e humanas, as quais já haviam sido exploradas e direcionadas de acordo com os interesses daquela sociedade.

Assim, as mudanças antropológicas, religiosas, filosóficas e científicas, ocorridas no decurso da história, fornecem-nos os subsídios teóricos para a compreensão do projeto modernizante que a Europa aspirou para o mundo.

A modernidade atinge o seu auge no Iluminismo, que por sua vez prega a centralidade da razão, renegando o passado e vendo no futuro um elemento libertador. O manifesto de Immanuel Kant (17241804), sobre o Iluminismo, publicado em 1784, é um ícone desse ponto de vista.

Diz Kant:

O Iluminismo é a libertação do homem de sua tutela auto-imposta. A tutela é a incapacidade do homem de usar seu entendimento sem a direção de outros. Auto-imposta é essa tutela quando sua causa não está na falta de razão, mas na falta de resolução e coragem para usá-la sem a direção dos outros. Sapere aude! Tem coragem de usar tua própria razão!- este é o lema do iluminismo.[...] Pelo uso público da razão de um indivíduo eu entendo o uso que a pessoa faz dela como um intelectual perante o público leitor (apud ENGELHARDT, 1998, p.28).

Logo após a Revolução Francesa até a Primeira Guerra Mundial, consolidaram-se o apoio e a total confiança no progresso e na ciência. A concepção de progresso trouxe ao ser humano a mentalidade e o vigor de que estavam construindo um novo mundo por meio de uma ciência, a qual traria conforto e bem-estar à humanidade.

Para Maar (1984), Kant, ao elaborar o seu ensaio sob o título $O$ que É Esclarecimento?, classifica a modernidade como o período em que a humanidade tem a oportunidade de sair por si mesma, com apoio dado pela autonomia da razão, do seu estado de heteronímia originado por ela mesma. 
Entretanto, o segundo sentido da modernidade foi gestado a partir do pensamento de Friedrich Nietzsche. A modernidade é vista como aquela que impõe uma cultura oponente e se autoduvida da crença na razão para cujo fortalecimento ela mesma deu sustentação. Esse período, para alguns teóricos, é chamado de pós-modernidade.

No entanto, centraremos a nossa reflexão mais especificamente na questão da modernidade. Tentaremos assim demonstrar as conseqüências do seu projeto socioeconômico para a sociedade.

Ao analisarmos $O$ egoísmo maduro e a insensatez, de Barcellona (1995), constatamos que dentro do cenário da objetividade científica moderna, a vontade de poder ressurge com mais intensidade. Essa vontade de poder sociologicamente se expressou nas formas de domínio capitalista da ciência e da natureza, impedindo o desenvolvimento de qualquer outro tipo de modelo de processo produtivo ${ }^{2}$. Ele crê somente nas suas leis, como se dá na ciência moderna. Assim, o impor-

${ }^{2} \mathrm{O}$ modelo capitalista de produção e de consumo é tipicamente moderno. Ele foi gestado a partir do surgimento e fortalecimento econômico político da burguesia. A máxima capitalista é o livre mercado e a sua mão invisível que teoricamente alocaria recursos e os distribuiria à população. A prática desse mecanismo durante a Revolução Industrial acabou gerando o que ficou conhecido como a questão social. É, então, devido às desigualdades na distribuição e acesso aos bens e riquezas do capitalismo que outros modelos de produção também modernos foram propostos. Entre os mais discutidos, está o socialismo de Proudon e Fourrier, que pretendeu somente uma reforma do capitalismo. Já o socialismo marxiano não pregava a reforma do capitalismo, mas a sua total superação pelo modelo comunista. No entanto, o capitalismo nunca permitiu uma experiência comunista propriamente dita. Ele sempre combateu o avanço do socialismo no mundo. A organicidade interna do sistema capitalista fez e faz com que ele se imponha diante da "ameaça comunista". Assim, temos a experiência de capitalismo de Estado apresentado por Keynes após a crise de 1929. Há também - Plano Marshal de reconstrução econômica da Europa, devido à destruição causada pela Segunda Guerra Mundial. A oposição entre socialismo e capitalismo acabou tornando-se uma guerra ideológica: a Guerra Fria. O Well-fare State indica também a não-trégua neste embate. Guerras como a do Vietnã e Afeganistão e embargos econômicos a paises socialistas como Cuba são emblemáticos dessa oposição ideológica. Com a Queda do Muro, em 1989, símbolo da derrocada socialista, o capitalismo mais uma vez se organiza. Ele agora é global e ortodoxamente neoliberal. Capitalistas celebram a vitória sobre o socialismo, ampliando mercados em países antes considerados inimigos. Até quando isto durará, dependerá de como os capitalistas tratarão a antiga e sempre nova questão social. 
tante para esta ciência é o seu método que se expressa na objetividade das análises e na verificação de todas as hipóteses científicas.

A racionalidade científica provê-se da sua metodologia que é fruto de sua época. O próprio padrão cultural vigente na modernidade divulgava a idéia de uma racionalidade na ciência. Tal racionalidade vai além da coleta de dados e fatos. Ela se evidência como possibilidade de relação verdadeira com a realidade, não apresentando nenhuma distinção entre a noção de real-ideal, liberdade-autoritarismo, natural-artificial.

Segundo Ianni (1988), desde o século XVIII e mais acentuadamente ainda, no século XIX, os progressos na ciência afloram de tal maneira que a razão parecia dominar e apagar por vez a fé, ficando o ser humano órfãos de Deus. As obras criadas pelo indivíduo são vistas como coisas dotadas de vida própria. Elas adquirem um novo sentido. O cálculo cientifico, a metodologia da ciência moderna, produz uma racionalidade, que tenta deixar claro a essência das coisas, bem com a fragilidade humana. O indivíduo, portanto, sente-se o senhor do seu destino, o futuro talvez esteja ao alcance que é dado pela razão, já que por meio dela ele pode captar, compreender, explicar e ordenar o mundo. Mais que isso, confere forma e sentido ao mundo.

Percebemos que tal fé na ciência levou ao endeusamento do progresso tecnológico. Acerca disso, Macaulay, em 1837, já afirmava:

A ciência abrandou o sofrimento, venceu as doenças, aumentou a fertilidade do solo, deu novas armas ao guerreiro, iluminou a noite com o esplendor do dia, ampliou o alcance do olho humano, acelerou o movimento, reduziu as distâncias, facilitou as comunicações, a condução dos negócios e assim por diante.A ciência é incansável. A sua lei é o progresso. (apud IANNI, 1989, p.20)

O que constatamos, então, é que a ciência forneceu elementos para o ser humano superar o medo de realidades envoltas em mistérios e superstições. Vale ressaltar também que o antigo e o novo "desconhecidos" muitas vezes eram criações do próprio indivíduo e frutos de suas ações.

A ciência e a racionalidade modernas possibilitaram ao sujeito obter o domínio dos seus atos, induzindo-o a pensar que o progresso teria todas as fórmulas mágicas para solucionar os seus dilemas espirituais e materiais. O ser humano acreditava que a razão moderna era o único 
instrumento de crítica capaz de libertá-lo, sobretudo das amarras da natureza, das forças espirituais e dos vícios morais e enfermidades sociais, proporcionando alívio para o processo existencial da espécie humana. Diante dessa crença a classe burguesa despontou nas esferas economias e políticas, dominando (financiando) a ciência e direcionando a técnica para os seus interesses políticos e econômicos. Este processo ideológico acabou criando problemas sociais e reduziu a ética a uma questão de livre produção e consumo. O indivíduo se perde neste processo. Os seus valores são sufocados em nome de um mercado e de uma técnica científica, estabelecendo uma racionalidade pró-burguesia.

Para Engel e Marx, a burguesia rasgou o véu das relações familiares, reduzindo a uma relação monetária e deu formas às novas classes sociais que estariam em condições de submissão constantes à burguesia.

No Manifesto Comunista, Engel e Marx (1989, p.10), perguntam:

em que se baseia a família burguesa? No capital, no lucro privado. Na sua plenitude, ela existe apenas para a burguesia; mas encontra seu complemento na ausência forçada de família entre os proletários e na prostituição .

Sobre esta questão de como a burguesia estabeleceu uma nova racionalidade, Engel e Marx $(1989$, p.11; 14) afirmam categoricamente:

As relações rígidas e enferrujadas, com suas representações e concepções tradicionais, são dissolvidas, e as mais recentes tornam-se antiquadas antes que se consolidam. Tudo o que era sólido desmancha no ar, tudo que era sagrado é profanado, e as pessoas são finalmente forçadas a encarar com serenidade sua posição social e suas relações recíprocas. [...] Com o desenvolvimento da burguesia, isto é, do capital, desenvolve-se também o proletariado, a classe dos trabalhadores modernos, que só sobrevivem se encontram trabalho, e só encontram trabalho se este incrementa o capital. Esses trabalhadores, que são forçados a se vender diariamente, constituem uma mercadoria como outra qualquer, por isso exposta a todas as vicissitudes da concorrência, a todas as turbulências do mercado.

Podemos perceber diante do exposto por Marx que a burguesia, para se manter no poder e ter o domínio de todas as esferas, muda 
constantemente as relações de produção, bem como as relações sociais. Ela consegue sucesso nessa tarefa, já que de acordo com Santos a burguesia astutamente separou a razão do sujeito. A filosofia moderna positiva tornou-se ideologia da classe dominante burguesa.

Como ponto de partida, esta filosofia moderna sentia-se orgulhosa por ser realmente um instrumento de "dedução e explicação e revelação do conteúdo da razão, enquanto imagem refletida e real na natureza e das coisas que conduz a vida"(HORKHEIMER, 1977, p.26). Esse movimento permitiu que também a ciência e a técnica fossem manipuladas. Ao progresso tecnológico foi impresso um irracionalismo que violentou a vida natural, vegetal, animal e humana. Acrescenta ainda Horkheimer (1977, p.194): "agora que a ciência nos ensinou a superar o medo diante do desconhecido, somos escravos de coações sociais que nós mesmos temos criado".

Nesse caso, notamos que a razão científica - que deveria ser usada em favor da humanidade e corresponder tudo aquilo que o homem desejava - não é senão um elemento de uma suprema irracionalidade econômica, provando o caos em todas as esferas sociais. Além do mais, a ciência moderna, segundo Horkheimer, é aquela atividade que torna a vida e tudo o que a cerca em coisa. Este modelo cientifico de produção, como já dizemos anteriormente, é parte da primícia de uma razão que ao longo de sua existência tem conseguido transformar o produto das atividades humanas em mercadoria. E para reforçar esta idéia, Bernal (1958, p.181) nos diz:

Os verdadeiros governantes de todos os paises capitalistas têm tratado a ciência como uma escrava útil e dócil, e muitos cientistas importantes estão mais que dispostos a aceitar este papel. Mas, a ciência utilizada desse modo só pode servir para aumentar a miséria e as dificuldades por que atravessa a civilização.

Deste evento, decorre o processo de mercantilização da vida humana e de suas relações. Isto aos poucos tece um modelo, um sistema de produção, no qual a vida é menos importante que um objeto do mercado. O ser humano seguindo esta lógica imposta não passa, portanto de um simples emaranhado de tecidos de células. Ele se torna um objeto qualquer, sem ética ou existencialmente valorativo, podendo ser manipulado 
à vontade. Sobre isto fala Rêgo e Bastos $(1999, \mathrm{p} .48)$ quando escrevem: "pois bem, do progresso da ciência depende diretamente todo o progresso da humanidade. Quem obstrui a ciência obstrui a humanidade. E aquele que o faz, que caráter revela diante de seu tempo? [...]".

Esse questionamento, segundo Horkheimer, é de extrema importância, uma vez que o progresso científico e a sua aplicação dependem das intenções daqueles que os manipulam ideologicamente ou não. De fato, se queremos aplicar conscientemente a ciência nos problemas humanos, temos que mudá-la, tal como ela muda a sociedade e as suas relações com a natureza.

De antemão constatamos que um grande mal-estar nos incomoda: afinal, qual o papel do intelectual?

Ao descortinarmos o véu da racionalidade moderna e analisar o desenvolvimento da ciência na modernidade, vemos que são poucos os intelectuais preocupados com o respeito à vida e à natureza. A maioria dos intelectuais, por sua vez, aceita as normas mercadológicas da ciência positiva.

Para Rêgo e Bastos (1999, p.49), "de tudo a humanidade pode prescindir; tudo pode ser lhe roubado sem ameaçar a sua dignidade, com exceção da possibilidade de aperfeiçoar-se". Não estamos discutindo se deve fazer ciência ou não. Afirmamos que ciência deve ser feita, sim. A ciência à qual nos referimos não é aquela direcionada por interesses econômicos e políticos, mas sim aquela que é respaldada por uma educação à qual todos os ramos do seu desenvolvimento contribuam para que o ser humano tenha os elementos necessários para o desenvolvimento científico e técnico, marcado por sua dignidade étic0a.

Certamente devemos lutar contra esta ciência da dominação. O caminho se inicia através de uma auto-reflexão crítica da educação que estamos recebendo. Os passos seguintes, segundo Rêgo e Bastos, passam pela proposta de uma nova forma de se educar, a qual leva a pessoa humana ao sentimento de suas verdadeiras necessidades ensinando os meios pelos quais elas podem ser satisfeitas. É, portanto, A educação que revela ao indivíduo que é possível para ele não satisfazer do seu descontentamento, não se abandonar ao tédio, ao desespero, à revolta, à violência, que o indivíduo pode decidir de por o problema de senso segundo a razão ao nível do discurso (KIRSCHER, 1989, p.21). 
Neste contexto histórico, vemos claramente que a razão reduzse em nossos dias ao controle técnico da natureza e dos indivíduos, fruto de uma ciência moderna que fortalece o surgimento de um mundo marcado por uma banalização da vida humana, pois argumenta Horkheimer (1977, p.116) que "em nenhum momento o conceito de eu se livrou da mácula da sua origem de um sistema de domínio social". A razão está inserida nas relações de trabalho e dominação, que torna mais uma vez o sujeito um simples acessório da máquina produtiva. A mecanização, portanto, impede nas palavras de Adorno (1999, p.8), “a formação de indivíduos autônomos, independentes, capazes de julgar e de decidir conscientemente".

Tenhamos, portanto, a consciência de que

existem pessoas que lá embaixo, como servos, portanto, praticam atos que se destinam a perpetuar a sua própria servidão e se despem de toda a dignidade humana [...] contra isso se pode fazer alguma coisa, pela educação, pelo esclarecimento (ADORNO, 1986, p.45).

\section{Dilema Ético da Técnica}

Das análises precedentes, constatamos que o ser humano enfrenta em nossos dias um grande problema ético. O novo fenômeno sociológico é fruto de uma ciência dominada por uma razão instrumental que se inaugura na era da modernidade. Esse dilema consiste no fato do indivíduo não ter mais domínio sobre o seu próprio poder, uma vez que ele perdeu o controle sobre suas possibilidades de criação e autocrítica valorativa daquilo que faz.

Como já vimos anteriormente, a gênese da ciência e da técnica se encontra no medo que o ser humano sentia ao ter que enfrentar a natureza e no desejo racional de poder, a fim de submeter essa mesma natureza misteriosa.

Santos (1998) enriquece a discussão ao perceber que a técnica e a ciência dominaram o progresso almejado pelos projetos utópicos da modernidade, funcionando também e, sobretudo, como poderosas armas de contestação do reacionarismo das forças pré-modernas. Todo 
esse cenário facilitou o desenvolvimento e o endeusamento tecnológico. Entretanto, podemos dizer que ironicamente o indivíduo, ao se desapegar de suas condições de homo natura, homo religiosus, tornando-se homo faber direcionado a viver como verdadeiro homo sapiens, segundo alguns estudiosos, encontram-se na dramática situação de homo consumens ou ainda de homo technologicus.

A vida das pessoas não é mais referida a critérios éticos e políticos, mas a critérios puramente técnicos de orientação econômica produtiva. Isso é causado pelo próprio sistema em que vivemos, o capitalismo, pois ele busca a mercantilização universal e a produção da mais-valia. O efeito desse processo aético é a dominação da coisa sobre o trabalho vivo, a do produto sobre o produtor. A mercadoria, elemento fundamental e resultado da coisificação das relações éticas de produção, apresenta-se como se tivesse características exclusivas e independentes daquele que a produz, que a cria: o ser humano.

Essa situação nos leva a compreender a alienação do sujeito perante a produção consumista, que é voltada somente para a " [...] disponibilidade técnica da coisa [...] e então exprime a vontade de manipular a natureza para tornar-se um objeto construível e destrutível, uma coisa que pode ser e não ser (toda coisa é um não - nada, enquanto produto - criado, que torna a ser nada)" (BARCELLONA, 1995, p.140).

Mais uma vez o sentido ético do ser em relação à técnica é colocado em risco. O ser humano está destinado a viver imerso neste sistema de dominação, em outras palavras, aprisionado em jaula de ferro, a não ser que se tenha um elemento central que forneça subsídios para uma possível reflexão da relação entre homem, poder e técnica.

No entanto, dentro deste contexto de crise, o que se constata é o reaparecimento do desejo de poder que se expressa na forma do domínio capitalista da ciência e da natureza, impedindo, por sua vez, outras formas de socialização. Barcellona (1995, p.143) comenta: "a primeira verificação concreta sobre como se mede a cultura do limite com a vontade de poder da técnica pode-se encontrar na relação entre 'máquina e 'natureza'”. Existe, portanto, uma técnica que destrói não só a natureza, mas os movimentos do ecossistema, buscando somente o lucro e a manutenção do seu poder. 
Com isso, temos uma perda imensa de tudo o que se produz, já que tudo se consome sem sequer deixar resquícios e significados. As pessoas não conseguem perceber o quanto o seu pensar ético e suas habilidades de trabalho que realizam cotidianamente estão alienadas. Nós nos esquecemos, de certo modo, dos desejos, das paixões. Tudo fica submetido ao um processo de uma racionalidade individual instrumentalizada ideologicamente e sem ética.

Horkheimer (1977, p.143) alerta-nos sobre a "circunstância cega da técnica no seu desenvolvimento, que é acentuado por uma opressão e exploração sociais que ameaçam, em cada etapa do progresso o seu contrário, a plena barbárie". Com isso, vemos claramente que o período em que vivemos está centralizado num enorme poder industrial de produção. A técnica aética tem como causa final a destruição do ser humano e da natureza. Esta mesma técnica ainda induz propositalmente o indivíduo a uma não-reflexão acerca do sistema em que se encontra imerso. As máquinas, por sua vez, também foram pensadas de forma a contribuir para o estabelecimento do trabalho alienado. Os trabalhadores são oprimidos todos os dias e horas pela máquina, pelo supervisor de produção, é claro pelos proprietários das fábricas.

Certamente este modelo tecnológico e de controle sobre produção e produtor tornou-se uma vantagem considerável para a burguesia organizar a sociedade de acordo com os seus interesses, já que o ser humano se encontra preso nas amarras da técnica devido a uma certa crença exacerbada na razão moderna de alguns de seus antepassados. Sobre isto, Adorno (1986, p. 42)diz:

\begin{abstract}
As pessoas tendem a considerar a tecnologia como algo em si, como fim em si mesmo, como uma força com vida própria, esquecendo-se, porém, que se trata do braço prolongado do homem. Os meios - e a tecnologia é a essência dos meios para a auto-preservação da espécie humana - são fetichizados, porque as finalidades - uma existência digna do ser humano - são encobertas e arrancadas da consciência humana.
\end{abstract}

Com o fetichismo, o ser humano não se emancipa de si mesmo. Ele é um prolongamento e ampliação do fetichismo do capital. O indivíduo coisificado fica preso em suas criações mirabolantes, conseqüên- 
cia de uma cultura do confinamento racional instrumentalizado, em cuja estrutura ideológica, a tecnologia ocupa posição clara e definida. Marx, um crítico da técnica, comenta na obra Lineamentos Fundamentais da Crítica da Economia Politica:

O pleno desenvolvimento do capital realiza-se portanto - ou o capital está junto e determina a forma de produção adequada para ele - só quando o meio de trabalho não só é determinado formalmente como "capital fixo," mas é suprimido na sua forma imediata, e o capital fixo apresenta-se em face do trabalho, no interior do processo de produção, com a máquina. E o inteiro processo de produção não se apresenta como mantido sob a habilidade imediata do operário, mas se apresenta como empenho tecnológico da ciência. Dar à produção caráter científico é, portanto a tendência do capital e o trabalho imediato é reduzido a um simples momento desse processo (apud BARCELLONA, 1995, p.141).

O modo de produção, então, advindo de qualquer racionalidade (em nossa reflexão, a racionalidade moderna que produz um modelo tecnológico, alicerçado em uma ciência ideológica), gera o processo social, político e espiritual da vida. É por isso que Marx nos fala que não é a nossa consciência que determina o nosso ser, mas sim, o nosso ser social que determina a nossa consciência.

Verificamos que esta crítica marxiana da técnica destaca a necessidade de colocar a tecnologia no parâmetro da historicidade e criticidade. A história nos fornece a racionalidade ética de uma nova tecnologia, enquanto que a crítica garante os limites da ciência. Ética e crítica colocam o ser humano no centro do processo econômico e político da sociedade, na qual ele deixa de ser meramente uma peça do processo de produção.

É interessante ainda observar que o capital, no grau elevado da sua loucura produtiva, reproduz a si mesmo, tornando o ser humano supérfluo. E neste desenvolver-se bruscamente, a tecnologia acompanha desesperadamente os interesses do capital, fazendo o jogo da racionalidade positivista. Como era previsto, a técnica não leva sequer em consideração o equilíbrio da sobrevivência humana dentro destes complexos processos éticos de relação entre indivíduo e técnica. Pode- 
mos assim dizer com o autor: "[...] a crítica da técnica não é, nestes termos, uma pura recusa da moderna tecnologia em nome de uma neoromântica ou irracional do vivente humano e não humano, mas uma diferente ordem possível, ainda em virtude de inaudito poder da técnica moderna" (BARCELLONA, 1995, p.144).

Devemos ainda ter a consciência de buscar indicações seguras para saber discernir o que realmente tem valor nessa situação vital de transformações frenéticas ou até mesmo caóticas. Afinal, queremos a preservação da liberdade e da dignidade da nossa existência diante da técnica de racionalidade economicamente ideológica. Neste sentido, Barcellona (1995, p.145) diz que devemos "decidir fixar o olhar sobre o vídeo da máquina pensante ou, como dizia Feuerbach, voltar os olhos para o céu: nada nos diz que coisa é melhor, mas sabemos que ela vai além de nós próprios".

Historicamente as atuais circunstâncias nos indicam que este é o momento para a reflexão sobre questões éticas implícitas nesta racionalidade técnica instrumental. E mais ainda, nossa ação deve ser efetiva de acordo com uma axiologia centrada na dignidade da vida humana. Ou seja, a análise ético-fillosófica das nossas ações diárias deveria ser tão profunda a ponto de não só interpretarmos a sociedade contemporânea, mas também transformá-la, como diria Karl Marx. 


\section{Referências}

ADORNO, Theodor W.; HORKHEIMER, Max. La Sociedad. Leciones de Sociología. Buenos Aires: Editorial Proteo, 1971.

. Educação após Auschwitz. In: COHN, Gabriel. et al. Adorno. Ática: São Paulo, 1986. p.33-45.

Os pensadores. São Paulo: Nova Cultural, 1999.

BARCELLONA, Pietro. O egoismo maduro e a insensatez. São Paulo; Ícone, 1995.

BERNAL, D. J. La Libertad De La Necesidad. México: Universidad Nacional Autonoma de México, 1958.

ENGELHARDT JR, H. Tristram. Fundamentos da Bioética. São Paulo: Edições Loyola, 1998.

ENGELS, Friedrich; MARX Karl. O Manifesto do Partido Comunista. Petrópolis: Vozes, 1989.

FREUD, Sigmund. El Porvenir de uma ilusion. In: - Obras Completas. Madrid: Editorial Biblioteca Nueva Madrid, 1948. p.1227-1299.

HABERMAS, Jünger. Horkheimer y Adorno: el entrelazamiento di mito e Ilustración. In: . El Discurso Filosófico de la Modernidad. Doce Lecciones. Altea: Taurus Ediciones, 1989. p.135-195.

- Un argumento contra la clonación de seres humanos. Tres réplicas.

In: - La Constelación Posnacional: Ensayos Políticos. Paidós: Biblioteca del Presente, 1998. p.207-221.

HORKHEIMER, Max. Sociedad en Transición: Estúdios de Filosofía Social. Barcelona: Ediciones Península, 1976.

La Critica de La Razón Instrumental: De conferencias y notas desde el final de la guerra. Buenos Aires, SUR, 1977.

IANNI, Octavio. A Sociologia e o Mundo Moderno. Tempo Social: Revista de Sociologia, São Paulo, n.1, p.7-27, 1979.

Karl Marx. São Paulo: Ática, 1988.

KIRSCHER, Gilbert. Orientarsi, Filosofare con Eric Weil. Prassi: Instituto Italiano per gli Studi filosofici. Come orientarsi nel mondo. Quatroventi, 1989. 
MAAR, Wolfgang Leo. Educação Crítica, Formação Cultural e Emancipação Política na Escola de Frankfurt. In: PUCCI, Bruno et al. Teoria Crítica e Educação: A questão da formação cultural na Escola de Frankfurt. São Paulo: Vozes, 1984, p.59-81.

MARX, Karl. Capitulo VI Inédito de O Capital: resultados do processo de produção imediata. São Paulo: Moraes, 1969.

REGGO, Walquíria D. Leão; BASTOS, Elide Rugai. A moralidade do compromisso. In: Intelectuais e Politica: a moralidade do compromisso. São Paulo: Olho dágua, 1999. p.7-41.

SANTOS, Edivan, P. Neoliberalismo na Crise da Modernidade. 1998.

Monografia (Especialização em Filosofia) - Fundação Educacional de Brusque, ESES, Santa Catarina.

\section{Abstract}

This paper shows a discussion on how and why, nowadays, ethics and science find themselves separated. We'll treat about the building up of a scientific rationality that has intended to be ethically neutral, and the social-cultural consequences of this modern sciences posture. Our study is based on the analyses developed by the Critical Theory over reason and modernity, principally on the concept of instrumentalization. In this same perspective, we'll also do some considerations about the matter of the ideology present in the sciences, that is, about the manipulation of sciences to keep economical-political interests of the hegemonic class. Instrumentalization and ideological usage will be highlighted as processes that have generated the lacking of ethical meaning in the sciences, making them a menace to all living beings in the planet, phenomenon that indicates the urgent necessity of ethical reflection on power and limits of the sciences.

Key words: science; modern reason; instrumentalization; ideology; ethics. 